\title{
Writing Activities Embedded in the Teaching Method Reform of Mechanical Manufacturing Course to Improve Students' Scientific Writing Ability
}

\author{
Jiming Zhou ${ }^{1, \text { a }}$, Lehua $\mathrm{Qi}^{1, \mathrm{~b}}$ \\ ${ }^{1}$ School of Mechanical Engineering, Northwestern Polytechnical University, Xi'an, 710072, China \\ aemail: zhoujm@nwpu.edu.cn, bemail:qilehua@nwpu.edu.cn
}

Keywords: Scientific writing; educational strategies; undergraduates; writing across the curriculum; education reform

\begin{abstract}
Scientific writing is an important way to accumulate and pass knowledge. It should be focused by numerous researchers. The feasibility and implementation ways of in-course scientific writing activities are discussed in this paper. It can be a useful reference for educators to find an efficient way of scientific writing training in university
\end{abstract}

\section{Introduction}

Scientific paper is a very important communication medium between scientific researchers, and plays very important role on the rapid development of science and technology. The ability to present scientific findings in scientific paper in an accurate, informative, coherent and logical manner is a core skill needed by scientists [1]. Distinguished chemist Lu Jiaxi thought that one can not be a qualified scientific researcher who can only create something but not express them very effectively. At the end of 1970's, distinguished scientist Hsue-Shen Tsien, Zhou Peiyuan, Su Buqing proposed to improve the scientific writing skill of younger researchers. Hsue-Shen Tsien suggested that Scientific Writing Course should be opened in universities or colleges. More important is that we need cooperative writing more than independent writing so that we can complete one project successfully together.

Unfortunately, people pay less attention on the training of scientific writing skill which is caused by not only students themselves but also instructors in university. The lack of scholarly writing skills is common upon graduate students, and typically the instruction of the process and technical aspects of scholarly writing is not emphasized until the dissertation [2]. A survey of 215 introductory biology students at the University of Wisconsin- Madison found that $45 \%$ did not like writing even though $98 \%$ of the students considered science writing important [3]. When the scientific writing was mentioned in universities from China, maybe scientific writing in English was more often recalled by many people. Such of these courses often were taught by teachers from Foreign Colleges who did not take part in the research activities in their career. The current state is that students from engineering universities or colleges are less skilled in scientific writing. One investigation report from Education Bureau of Beijing showed that the quality of thesis or dissertation from 28 universities was not good as before. Consequently, it is imperative that students achieve critical competencies of scientific writing throughout their academic tenure in order to successfully articulate research in writing [4]. Zhang Ling et al [5] also have analyzed the undergraduate teaching scheme from MIT and proposed the suggestion about the adoption of in-course writing activities. Sue Samson and Kim Granath [6] hold the similar opinion as Zhang Ling. I have ever tried to embed the scientific writing training in the course of Mechanical Manufacturing. This paper reports the practice of the adoption of in-course writing activities and gives some thoughts about that. We hope it can be a beneficial reference for some other teachers in similar fields. 


\section{The Practice of Embedding Scientific Writing Training into the Course Teaching Process}

Students are required to look into the related information about some given topics, filter them, and summarize the core information in scientific paper format which is just like a review paper during in-course writing activities without increasing the course hours. The spare time and interest from students are the prerequisites for this activity. But under the current situation, these two conditions are hard to be satisfied, so the implementation of this activity involves many difficulties.

The in-course writing activity is realized in the teaching of Mechanical Manufacturing in which students were required to submit a review paper about how things around them were made. Students can submit their job in any time before the end of the semester, which makes sure that they have much of time to prepare the paper. During the stage of paper preparation, students have to review the learned knowledge, or to learn the new knowledge in advance. The scientific paper required to complete includes title, abstract, introduction, object description, principle of manufacturing, and possible modified methods. References are certainly needed at the end of paper. The results showed that the writing ability of students differed greatly. Some of them only copied related information from website and pasted them together without any rewriting and reorganizing. Especially, context was illogically. One elder professor from Tsinghua University felt very disappointment and said that it may be very difficult for students to describe the principle of the bicycle very clearly. In the followed next year, I asked students to submit one-sheet review paper as a writing skill training homework. The results were not satisfied yet.

The unsatisfied results from in-course writing skill training can not be the reason for us to give up this meaningful activity. We should keep this project going ahead and finally lead the students to realize the importance of scientific writing ability.

\section{Thinking from the Practice of In-Course Writing Skill Training}

Many reasons lead to the less ability of writing skill of students from engineering schools. It is the direct reason for students not paying much more attention on it. On the other hand, college officer also don't pay enough strength on the construction of scientific writing course. They thought the engineering practical ability and innovation ability are more important than the scientific expressing ability. Till now, there is no scientific writing course in many universities. Mei Jianfeng and $\mathrm{Xu}$ Min [7] pointed out three possible reasons which led the less scientific writing ability of students after analyzing the current status of students' ability to write scientific paper. One was that students did not take part in the systematic training from professional teachers; one was that students and teachers did not pay much attention on it, and the other was psychological fear about the writing. Qin Chengrong [8] thought that there was no major to study the scientific methodology, scientific investigation, and innovation for long time, which caused the lack of teachers with profound scientific investigation theory. Therefore, course scheme from university neglects the scientific writing.

Nowadays, there is less chance for students to do writing practice. While the college Chinese is taught in some university, it is different from scientific writing in many aspects. One can make big progress in scientific writing only after the long term training. Accumulation is more important than short term of preparation. We all have learned English for many years. Unfortunately, few people can use English to communicate with foreigner fluently. Why? It is the reason that we never use it in daily life. The same reason for poor ability of scientific writing is that students do not use it often; even for somebody never uses it.

In-course writing skill training is expected to be one of efficient way to improve the ability of students to write scientific paper. When it is combined with professional training of scientific writing, it will lead more satisfied results. 


\section{New Ways to Implement the In-Course Writing Skill Training}

\section{A. Transformation from textbook-based teaching to literature-based teaching}

The current teaching system is characterized as that students acquire the knowledge from teachers based on the textbook. It is excellent in the summarized systematic knowledge in the textbook. But students are limited in the range of textbook which usually neglects the interconnection between different disciplines. The knowledge students needed in their life is just like broad sea, while they maybe only get the swimming pool of knowledge. So teachers should teach students how to sail on the sea to find and master the necessary knowledge. It is not enough for teachers to teach students the swimming technique in swimming pool. In words, there is a famous saying in Laozi, "give a man a fish and you feed him for a day; teach a man to fish and you feed him for a lifetime".

Leaving textbook aside, teachers should teach students in inspiring, instructing way and let them know what the cores of the course are. Teachers only teach the difficulties presented before students when they learn by themselves. Specific knowledge points should be mastered by students themselves after class from broad informative resources, such literature, and website and so on. Students are required to summarize the knowledge in paper format and submit it to teacher as homework. In this way, students can master the skill of paper writing. Maybe the knowledge summarized by students is not systematic, and teachers should do comments on it and encourage them to conduct peer review.

Besides the textbook, students can acquire knowledge from journal paper, patents, monograph, website, newspaper, and magazine in Chinese or English.

\section{B. Transformation from knowledge point-based test to knowledge spectrum-based test}

Current examination is mostly based on the specific knowledge points for one course, which neglects the interconnection between different courses. Students forget almost everything after examination. Some students even forget they have studied the course. It is worthy for us to rethinking the current education system based on the sole course teaching with neglecting the interconnection between courses or discipline.

Talented person with the background of multidiscipline and innovation ability can be grown up under the instruction of talented teachers with more profound specialized knowledge and broad vision on science and technology. The most important thing teachers should do is to inspire the students' interest about this course. Students construct the knowledge system in their brain under the instruction of teachers in class. The more complex of this system is, and the broader of their knowledge is. Students will master more efficient studying methods. Students should broaden their knowledge based the constructed system.

Examination had better to be done by the combination of theoretical and practical knowledge. For engineering students, practical implementation of theoretical knowledge is the final target. We focused on the theoretical knowledge examination before, and neglected the importance of practice. After completing the study of one course, students can not apply the learned knowledge into the reality. In mechanical manufacturing course, different processing technologies have been introduced extensively in class by teachers, but students maybe do not know what the exact manufacturing process for specific article is in our daily life such as heater, pressure container and so on.

\section{Constructing peer review between students}

Communication between students can be an efficient way for improving the students' ability of studying. Students get knowledge from unfamiliar state to familiar state, and some key point which prevent students to understand the whole concept may be neglected by teachers. After the 
construction of knowledge system instructed by teachers, students acquire more knowledge by scientific writing on the basis of information searching. Scientific writing is the form of knowledge summarized by students. Students are encouraged to learn from each other through peer review. Teachers are still required to comment on the scientific writings done by students and give very specific suggestions to each one.

Students learn knowledge from the very beginning of direct under the instruction from teachers to the mastering of study method. Just like one child learn to walk from the assistance from other people to walk by themselves. Qian Weichang ever said that college education should lead students to acquire knowledge by themselves finally. Peer review is an important process of learning from each other. Students should benefit from peer review earlier.

\section{Difficulties in the implementation of new ways}

There are many difficulties in realizing the new ways mentioned before, especially for the transformation of new examination system. Compared with the standard test, knowledge spectrum-based test is not limited to the conventional form of filling blank, choice making, brief answering question and so on. Students can expand their vision on the exam. But this is hard to be accepted by students and teachers. Students are afraid the unfair from teachers and teachers would not put their much strength in the comment of students' work. So more efficient examination way need to be found out in future.

\section{Conclusions}

In-course scientific writing training has been practiced in the course of mechanical manufacturing. The students' ability of paper writing is low usually. It is very urgent to improve the writing ability of students in current day. Three different ways are proposed in this paper to do course reform by embedding the writing training in the course teaching stage. But more difficulties are presenting before the educator and required to be solved in near future.

\section{Acknowledgment}

This paper is supported by the Project of Shaanxi Higher Education Reform Research (No. 11BY08).

\section{References}

[1] S. E. Lee, Writing Activities Embedded in Bioscience Laboratory Courses to Change Students’ attitudes and Enhance their Scientific Writing [J]. Eurasia Journal of Mathematics, Science \& Technology Education, 2011(7)193-202

[2] R. S. Caffarella, B. G. Barnett, Teaching doctoral students to become scholarly writers: The importance of giving and receiving critiques [J]. Studies in Higher Education, 2000(25)39-52

[3] B. Manske, That's Not Biology... Or is it? Changing students' perceptions of writing in the sciences. from http://mendota.english.wisc.edu/ WAC, November 2010

[4] P. Collier, D. Morgan. “Is that paper really due today?”: differences in first-generation and traditional college students' understandings of faculty expectations [J]. Higher Education, 2008(55)425-446

[5] L. Zhang, K. M. Zhang, J. Z. Cai, Scientific quality, scientific research training and scientific writing [J], Journal of Xi' an Jiaotong University (Social Sciences), 2000(20)28-29 (in Chinese)

[6] S. Sue, G. Kim, Reading, writing, and research: added value to university first-year experience programs, Reference Services Review, 2004(32)149-156

[7] J. F. Mei, M. Xu, Scientific writing ability training and college students' quality education [J], Higher Education \& Economy, 2006(19)75-78 (in Chinese) 
[8] C. R. Qin, Thinking about the current status of scientific writing teaching in engineering school and some suggestion on the education reform[J], Journal of Guangxi University (Philosophy and Social Science), 2005(27)165-166 (in Chinese) 